\title{
Antecedentes y Evolución
}

\author{
Luiz Henrique Pereiro Do Fonseco \\ Embojodor de lo Repúblico de Brozil
}

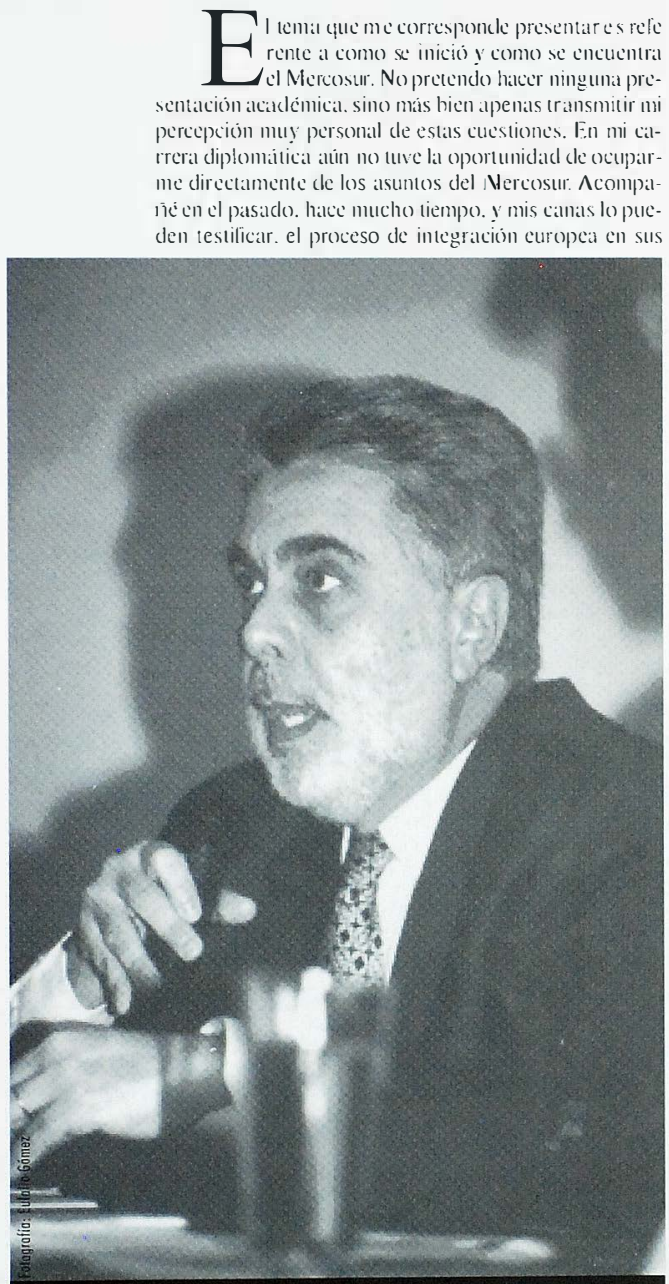

Luiz Henrique Pereira Do Fonseco. inicios. y. más recientemente. en 1989 y 1990 dirigi la D1vision cle América Meridional I en el Ministerio de Relaciones Extcriores, la cual se ocupa delCono Sur.

Con base en esıa experiencia de vida. y repilo, a liuulo personal. puedo decirles que esioy convencido de que el Mcrcosur lue el fruto de un exiraoidinario proceso cle accrcamiento entre Brasil y Argentina. Este acercamiento posibilitó los primeros pasos de la integración entre los dos paises. Io que funcionó como fuerza centripeta para una integración más amplia entre Brasil. Argentina. Uruguay y Paraguay, los miembros de Mercosur. Estoy seguro cle que posieriormente esa misma fucrza centripeta atraerá para el proceso de integración a Chile. a Bolivia y a los demás paises de la Comunidad Andina.

\section{La semilla del Mercosur}

¿Pero cómoocurrió estc acercamiento entre Brasil y Argentina que lue la semilla del Mercosur? Históricamente las naciones cle América del Sur nos dábamos las espalclas y nos quedábamos mirando más a los centros de poder en Europa y Estados Uniclos. El propio proceso de colonización cle Brasil no favorecia la integración con los demás vecinos. Brasil fue el tunico pais en la región colonizado por Portugal. mientras que los demás lo fueron por Esparia. Nuesıra independencia también fue mu! diferente a la cle los paises de la América Hispánica. Esta últuma sulrió un verdadero despedazamiento geográlico que origino varios paises. y' en cambio en Brasil se manIuvo la unidad icrritorial. Para huir de las guerras napoleónicas en Europa, la corte real se trasladó en 1807 hacia Brasil y asi la metrópoli se transfirió cle Portugal para Brasil. país que pasó a ser la secle del Reino Unido de Portugal y colonias africanas. Derrolado Napoleón. el Rey Don Joảo VI. contra su gusto tuvo que regresar a Portugal. pero dejó en Brasil a su hijo Don Pedro. quien acabó proclamando nuestra Independencia en 1822. De forma pacilica y no con guerras independistas como ocurrió con los demás latinoamericanos. Durante alguin tiempo Brasil era el único Imperio en las Américas. cercado cle Repuiblicas por todos laclos. hecho que creaba una desconfianza natural en relación con nucstros vecinos.

A partir cle la Preclamación de la República brasılcna a linales del siglo $X \mathbb{X}$. las relaciones de Brasil con Argentina pasaron a ser marradas por disputas y celos Tal siluación incómoda se intensificó por la unclustriali- 
zación de Brasil en la década de los 40 y por la construcción de la hidroclétrica de I taipú, la más grande del mundo, entre Brasil y Paraguay. Ese emprendimiento conjunto creó suspicacias en Argentina, donde algunos secIores alegaban que si Brasil quisiera abrir las compuertas de la represa, una gran parte del territorio argentino pudiera ser inundado.

El origen remoto del acercamiento de Brasil con Argentina sóloocurriria en octubre cle 1979, con la firma del acuerdo tripartito Argentina, Brasil y Paraguay, compatibilizando los proyectos hidroelétricos Itaipú y Corpus. En aquel entonces. el Presidente del Brasil, el último militar en el poder, General João Baptista Figueireclo, habia estudiado en Buenos Aires y tenia una admiración especial por el pais y por su gente. Estos datos personales explican un pocolos intentos hechos para superar las disputas existentes. Sin embargo, fue gracias al trio José Sarney, Raúl Alfonsin y Julio Maria Sanguineti, políticos de una misma generación, quienes llegaronal poder en una misma época y mantuvieron entre sí perfectoentendimiento, que intensificó el acercamien10 entre Brasil y Argentina. Fueron entonces creadas relaciones de confianza que propiciaron armonizar posiciones y coordinar la actuación en los diversos foros multilaterales.

\section{Los comités de fronteras}

Data de esta época la creación de los Comités de Frontera (tanto de Brasil con Argentina como con Uruguay y con Paraguay). Yo tuve la oportunidad de participar personalmente de la creación de esos Comités que considero un factor decisivo para las buenas relaciones entre países vecinos. Sin duda, se trata de un modelo que puede ser seguido en otras partes del mundo. Muy resumidamente, son Comités formados por autoridades de municipios vecinos de ambos paises y que tienen un canal de comunicación directo con las respectivas Cancillerías, con el objeto de trazar medidas administrativas en común. Asi, por ejemplo, en ciudades fronterizas en vez de mantenerse en cada una servicios de cuerpo de bomberos, de hospital, de bibliotecas, se unifican en una u otra ciudad esos servicios, que pasan a ser utilizados por las dos comunidades.

Quiero, en ese contexto, citar una experiencia de la cual participé personalmente que fue la construcción del puente uniendo Santo Tomé, en Argentina, a Sảo Borja. en Brasil. Como en aquella época los Gobiernos de Argentina y Brasil no disponian de recursos presupuestarios para la construcción del puente, las comunidades de las dos ciudades se unieron y presentaron un plan, por el cual ellas se encargarian de los gastos necesarios para la instalación del puente. Nuestros Gobiernos se limitaron a aprobar $y$ a proporcionar un marco jurídico legal para ese puente, que ya se encuentra en pleno funcionamiento. Muchas veces el Presidente Sanguineti, de Uruguay, intervenia para facilitar el entendimiento del Presidente Brasil, Sarney, con el Presidente de Argentina, Alfonsin. El entendimiento llegó a tal punto que ambos Presidente lanzaron la idea de una integración económica entre Brasil y Argentina.

Asi es que en julio de 1986 Brasily Argentina firman el Acta de Integración Econónica, sucesivamente ampliada en los atios posteriores. Se trataba del programa de integración y complementación económica que constaba de 24 protocolos, englobando los siguientes sectores:

\begin{tabular}{|c|c|c|}
\hline \multicolumn{3}{|c|}{ Sectores englobados en el Acta de integración Económica } \\
\hline - Bienes de capital & - Emergencias radiológicas & \multirow{3}{*}{$\begin{array}{l}\text { lanzamiento por los Priesidentes } \\
\text { Mlenem y Sarney del primer avión } \\
\text { "jet" labricado conjuntamente por } \\
\text { Brasil y Argentina). }\end{array}$} \\
\hline - Trigo & - Siderurgia & \\
\hline - Complementación de abastecimien- & - Transporte terrestre & \\
\hline & - Transporte maritimo & \multirow{7}{*}{$\begin{array}{l}\text { - Cooperación nuclear (fue también } \\
\text { mu,y impactante asistir a las visitas } \\
\text { conjuntas del Presidente de Argen- } \\
\text { tina a Brasil a las instalaciones nu- } \\
\text { cleares de ambos paises, áreas que } \\
\text { antes eran secretas; nada podria ser } \\
\text { más sintomático de las relaciones de } \\
\text { confianza que se establecian entre } \\
\text { nuestros paises). Y protocolos has- } \\
\text { ta aún en los sectores vitales de: }\end{array}$} \\
\hline - Expansión del comercio & - iranspor te marimo & \\
\hline - Creación de empresas binacionales & - Comunicaciones & \\
\hline - Asuntos financieros & - Cooperación cultural & \\
\hline - Fondos de Inversión & - Adninistración pública & \\
\hline - Energía & - Industria alimenticia & \\
\hline - Biotecnología & - Industria automotriz & \\
\hline - Estudios Econónicos & \multirow{2}{*}{$\begin{array}{l}\text { - Cooperación aeronáutica (fueemo- } \\
\text { cionante asistir en la sede de la em- } \\
\text { presa EMBRAER, en São Paulo, el }\end{array}$} & - Planeación económica y social y, \\
\hline $\begin{array}{l}\text { - Asistencia Reciproca en caso de ac- } \\
\text { cidentes nučleares }\end{array}$ & & - Creación de una moneda común. \\
\hline
\end{tabular}


Alli e nestos 24 Protocolos del Acta d el a Integración Económica, de julio de 1986. están las raices del Mercado Común del Sur. Todos los 24 Protocolos fueron absorbidos por el Acuerdode Complementación Económica $\mathrm{N}^{\circ} 14$, de diciembre de 1990, inscrito en la Asociación Latinoamericna de Integración (ALADI) y que representó un referencial para el Tratado de Asunción. Cabria agregar que en 1988 Brasil y Argentina suscriben el Tratado de Integración. Cooperación y Desarrollo que fue la base para la posterior Acta de Buenos Aires en 1990, la cual fijaba como fecha para la creación de un mercado común el 31 de diciembre de 1994. Con la incorporación de Uruguay y Paraguay en el proceso de integración, en agosto de 1990 se abandona el concepto de bilateralidad. Asi es que en el marco de los acuerdos preestablecidos entre Brasil y Argentina, nace el 23 de marzo de 1991, con el Tratado de Asunción, el mercado Común del Sur, el Mercosur, integrado por Argentina. Brasil, Paraguay y Uruguay.

\section{Conformación del Mercosur}

En contraste con otras formas menos ambiciosas de integración, tales como área de libre comercio o unión aduanera, nuestros Gobiernos decidieron crear un mercado común. El Tratado de Asunción de 1991 establece para la etapa final del proceso la libre circulación de bienes, de servicios y de factores de producción en el espacio común del Mercosur. Más de que una simple liberación del comercio intrazonal de bienes, se trata de una alianza estratégica.

Siendo un mercado abierto, el Mercosur representa un ejercicio que posibilitará otros procesos de integración : como por ejemplo, con la Comunidad Andina, con la Unión Europea, con el Mercado Común Centroamericano, con el NAFTA. Sin embargo, el Mercosur permanecerá siendo siempre un mercado común, mientras el Area de Libre Comercio de los Américas (ALCA), aunque geográficamente más amplio, en térrninos de integración es menos ambicioso pues se trata apenas de un área de libre comercio. Además, ya firmamos en 1996 acuerdos de complementación económica con Chile y con Bolivia que tienen por objetivo crear un área de libre comercio del Mercosur con estos paises. Ya se firnaron también acuerdos macros con la Unión Europea y con Centroamérica. El Mercosur funciona también como una especie de ensayo para los empresarios de los paises miembros para, a largo plazo, una liberación más amplia de los mercados de nuestras naciones, conforme viene exigiendo esta era de la globalización.

El Mercosur tenia conciencia de las malas experiencias de la Asociación Latinoamericana de Libre Comercio (ALALC), creada en 1960 y, posteriormente de la ALADI, (Asociación Latinoamericana de Integración), creada en 1980. Ambas instituciones tenian una estructura jurídica amplia y ambiciosa, pero carecian de una masa critica de intereses concretos que les posibilitara alcanzar los objetivos integracionistas. Por esto mismo el Mercosur intentó evitar esa mala experiencia y desarrollarse a partir del intereses concretos. La primera consecuencia de esa integración fue el extraordinario aumento de flujos comerciales. Sin embargo, las ventajas no sc encuentran solo en el campo econónico, sino también en lo político.

Comparada con la Unión Europea la experiencia del Mercosur es muy reciente, pues tiene apenas 9 años de existencia, mientras la Unión Europea tiene más de 43 años. En Europa el proceso de acetcamiento. fue más difícil porque se trataba de un área históricamente caracterizada por conflictos y guerra. Los padres del modelo europeo de integración no eran economistas, pero sí políticos. Europa unida era la única alternativa para enfrentar al mundo bipolar de aquel entonces. Es verdad que en algunos paises europeos los logros económicos representaban los verdaderos incentivos de la integración. pero nunca se debe perder de vista la dimensión política del proyecto.

Ese mismo comentario se aplica al Mercosur. También en Europa la integración se inició modestamente: el primer paso fue la Comunidad Europea de Carbono y Acero (CECA) en 1951. cl segundo, Unión Aduanera de Bélgica, Holanda y Luxemburgo (BENELUX). para sólo después ser aprobada, por los Tratados de Roma. firmados el 25 de marzo de $\$ 957$ y puestos en vigor a partir del $1^{\circ}$ de enero de 1958, la Comunidad Económica Europea, formada incialmente por 6 miembros BENELUX. más Francia. Alemania e Italia. Alli está la semilla de la Unión Europea de hoy, amplia y exitosa. Es un ejemplo a ser seguido por nuestros paises que buscamos también una mayor integración.

Tales como especificados en el Tratado de Asunción. son los siguientes los principales objetivos del Mercosur:

- La libre circulación de bienes, scrvicios y factores productivos entre los paises miembros.

- El establecimiento de un arancel externo común.

- La eliminación de barreras arancelarias.

- La coordinación de las políticas macroeconómicas y sectoriales.

Yo tuve el privilegio de conocer al gran economista Domingo Cavallo antes de él ser ministro de Relaciones Exteriores y Culto y posteriormente ministro de Economía de Argentina. Antes de asumir estas importantes funciones, ya se preocupaba por las relaciones entre Brasil y Argentina y, con su talento visionario, escribió un libro adonde presentaba una imagen que me parecia muy perspicaz.

Según él, los intentos de acercamiento entré nuestros paises (la creación dic comités de fronteras. Ios contactos de autoridades, cl establecimiento de relaciones 
bilaterales de confianza, etc.), eran como huecos en un gran muro que todavía separaba Brasil de Argentina. Su pro,puesta era no aumentar esos huecos, pero síir bajando poso a poco ese muro hasta la eliminación total. Estoy convencido de que el fortalecimiento de mecanismos ya existentes en el ámbito del Mercosur, deberá resultar de un proceso histórico natural y no apenas de un voluntarismo. Este fortalecimiento institucional ciertamente eliminará los pedazos del muro todavía existentes.

El año de 1999, en vista de la crisis linanciera internacional que af ectó seriamente a nuestros países, no propició progresos visibles en el Mercosur. No obstante, tal circunstancia testimonió la clara intención de nuestra naciones de superar las dilicultades y. siempre que sea necesario, ultrapasar obstáculos, como los enfrentados actualmente, para alcanzar sus objetivos más amplios.

\section{Los retos del Mercosur}

Actualmente el Mercado Común del Sur se enfrenta al reto de consolidación interna. Desde el $\mathrm{I}^{\circ}$ de enero de $1995 \mathrm{el} \mathrm{Mercosur} \mathrm{se} \mathrm{ha} \mathrm{constituido} \mathrm{en} \mathrm{una} \mathrm{unión} \mathrm{adua-}$ nera, aún incompleta, con un arancel externo común entre 0 y $23 \%$ para un $85 \%$ de todos los productos importados. Además de los éxitos en el campo económico, que pueden ser comprobados por las estadísticas, habría que acentuar los progresos en el campo político. En la XIV Cumbre del Mercosur, por ejemplo. se firmó un compromiso con la Democracia, una exigencia para sus miembros, - todos deben de practicar la Democracia -, y se proclamó el Mercosur como zona de paz. libre de armas y destrucción masiva.

Por otro lado, el Protocolo de Ouro Preto en 1994. reconoce la personalidad jurídica de Derecho Internacional del bloque del Mercosur y le da competencia para negociar con paises o grupos de paises u organismos internacionales. La integración del Mercado Común del Sur ya favoreció realizaciones en otros sectores. tales como : educación, justica, cultura, Iransportes, medio ambiente, energia, agricultura.

A ese respecto. me gustaria destacar algunos de los acuerdos ya alcanzados, como por ejemplo cl reconocimiento y revalidación de títulos y diplomas, la asistencia mutua en asuntos penales, el "sello cultural", entre otros. Es verdad que para algunos el proceso viene siendo len10, pero no tengo duda de que llegaremos a un nivel de integración tan amplio como se verifica actualmente en Europa. Ya hay consenso en cuanto a la necesidad de un día adoptar una moneda común (para la cual ya se habla del nombre "gaucho").

Conforme concepción general, serian las siguientes las principales ventajas del Mercosur desde la perspectiva política:

\begin{tabular}{|c|}
\hline Ventajas del Mercosur \\
\hline $\begin{array}{l}\text { - La definitiva desaparición de las hipótesis de con- } \\
\text { nlicto entre los paises de la región. }\end{array}$ \\
\hline $\begin{array}{l}\text { - Una garantia para los sistemas democráticos actual- } \\
\text { mente vigentes en cl Cono Sur. }\end{array}$ \\
\hline $\begin{array}{l}\text { - Una "red de seguridad"política e institucional sobre } \\
\text { la cual se desarrollan las relaciones económicas y } \\
\text { sociales. }\end{array}$ \\
\hline $\begin{array}{l}\text { - El fortalecimiento de los vínculos culturales enire los } \\
\text { pueblos de la región. }\end{array}$ \\
\hline $\begin{array}{l}\text { - El progreso hacia la consolidación de una identidad } \\
\text { regional única. }\end{array}$ \\
\hline $\begin{array}{l}\text { - El fortalecimiento del poder de negociación de la re- } \\
\text { gión en el escenario global. }\end{array}$ \\
\hline $\begin{array}{l}\text { - Además, es la principal estrategia para facilitar las } \\
\text { inserción de la región al proceso de globalización. }\end{array}$ \\
\hline $\begin{array}{l}\text { Y desde el punto de vista económico, } \\
\text { son las siguientes: }\end{array}$ \\
\hline - Una mejor asignación de los recursos productivos. \\
\hline - Mercados más amplios. \\
\hline $\begin{array}{l}\text { - Una herramienta útil para fortalecer y profundizar } \\
\text { las reformas económicas iniciadas por los diferentes } \\
\text { Estados miembros. }\end{array}$ \\
\hline $\begin{array}{l}\text { - Un mayor grado de complementación productiva, a } \\
\text { través de iniciativas empresariales conjuntas. }\end{array}$ \\
\hline $\begin{array}{l}\text { - Mayores incentivos para la inversión extranjera di- } \\
\text { recta. }\end{array}$ \\
\hline $\begin{array}{l}\text { - Mayor potencial para la integración de pequeñas y } \\
\text { medianas empresas a los mercados mundiales. }\end{array}$ \\
\hline $\begin{array}{l}\text { - Niveles más altos de ingresos de los consunidores, } \\
\text { garantizando el acceso a una variedad más amplia } \\
\text { de bienes y servicios. }\end{array}$ \\
\hline
\end{tabular}




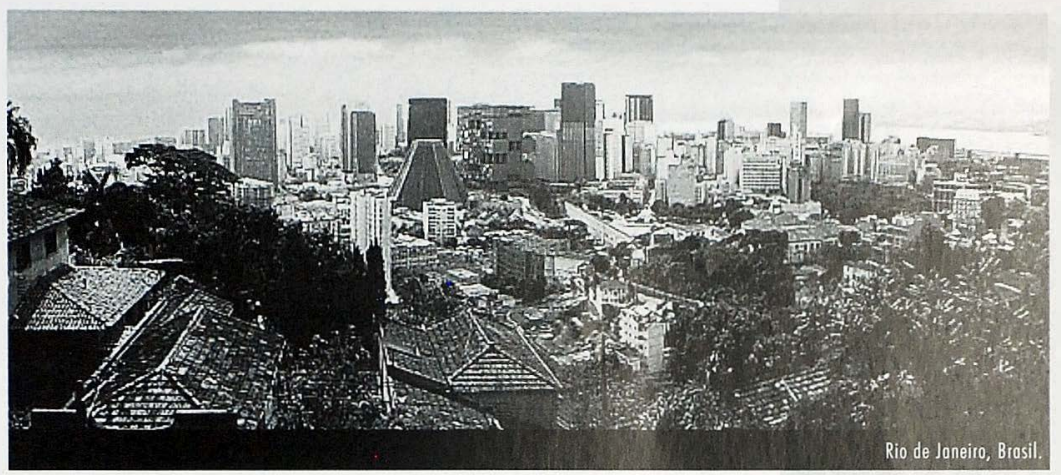

Las estadisticas revelan clarameme los logros y a alcanzados en estos 9 últimos anos. entre 1990 y 1998 el comercio in tramercosur pasó de 4.127 millones de dólares para más de 20.00. millones die dólares. con aumento de casi 5 veces. Este comercio entre los 4 países representa casi el 30\% del total de ventas del Mercosur.

Las exportaciones extranjeras del Mercosur tambicin crecieron de 42.000 millones de dólares en 1990 parial 62.000 millones de dólares en 1997.

Porotro lado el Producto Interno Bruto del Mercosur en 1998 ya alcanzaba la cifra significativa de 1.146 millones de dólares, el cuarı más grande del mundo (después del NAFTA. Unión Europea y Japón).

Cabria aún mencionar otros datos interesantes. EI Mercosur representea el $70 \%$ de 10 do el territorio de América del Sur y el $64 \%$ de su población. $\Lambda$ demás. el Producto Interno Bruto del Mercosur representa el 59\% de la suma de productos de todo los paises de América Latina.

En relación a los recursos naturales de todo el mundo. el Mercosur posee:

- $14.9 \%$ de las áreas forestales

- $17.6 \%$ de ganado

- $32 \%$ de sova (mayor exportador de aceite y harina de soya).

- Mayor exportador mundial de café. azuicar. aceile dc girasol. jugo de naranja. de limón.
El comercio de Brasil con Argentina. también se be nel ìció del Mercosur: en 1987 era cerca de 1.400 millones de dólares subió en 1991 para 3.000 millones de dólares y en 1996 para 12.000 millones de dölares, volviendo a Argentina el segundo principal mercado individual para las exportacioncs brasileias ( 5.017 millones cle doblares en 1996 ó cerca del $11 \%$ del total de las exportaciones brasilenas). Brasil. que en 1990 exportaba para Argentina. Paraguay y Uruguay 1.300 millones de dólares paso a exportar 7.300 millones de d6lares para esos mismos mercados en 1996.

\section{Las crisis del Mercosur}

A pesar de la desvalorización del Real. Argentina continúa teniendo superávit en comercio con Brasil y no se confirmarón los pronósticos alarmantes de que Brasil. después cle la desvalorización del Real, inundaria a los demés paises del Mercosur con sus productos.

La crisis momentínea por la cual estamos pasando en el Mercosur es un hecho natural en cualquier proceso de integración que surge en épocas de difícultades.

La Unión Europea tambièn enfrentó ! deberia seguir enfrentando crisis iemporales. Sin embargo. la dificil situación actual podrai aun propiciar. a corto plazo. un verdadero relanzamiento del Mercosur (y quiero subravar la expresión "relanzamicnto del Mercosur" mu! utilizada últimamente por las autoridades de nuestros Gobiernos). ya yue tod das las encuestas de opinion dejan bien claro el interes de los pucblos de nucstros + paises en sus mis diversiss clases sociales - de seguir adelante con el modelo de integración y de ultrapasar asi obsticulos temporiles. 